ISSN 0103-5150

Fisioter. Mov., Curitiba, v. 24, n. 2, p. 255-263, abr./jun. 2011 Licenciado sob uma Licença Creative Commons

\title{
Efeito agudo da técnica de reeducação postural global na postura de mulheres com encurtamento da cadeia muscular anterior
}

\author{
Acute effect of global posture reeducation technique in the \\ posture of women with anterior muscular chain shortening
}

\author{
Luciano Pavan Rossi ${ }^{[a]}$, Michelle Brandalize ${ }^{[b]}$, Anna Raquel Silveira Gomes ${ }^{[c]}$ \\ [a] Doutorando Universidade Federal do Paraná (UFPR), professor da Universidade Estadual do Centro-Oeste (UNICENTRO), \\ Guarapuava, PR - Brasil, e-mail: lucianofisioo@yahoo.com.br \\ [b] Mestre, professora da Faculdade Guairacá (FAG), Guarapuava, PR - Brasil, e-mail: michelleb_fisio@yahoo.com.br \\ [c] Professora Doutora da Universidade Federal do Paraná (UFPR), Curitiba, PR - Brasil, e-mail: annaraquelsg@gmail.com
}

\section{Resumo}

Introdução: A reeducação postural global (RPG) é um método de avaliação e tratamento das diversas disfunções posturais, que utiliza posturas globais para tratar as cadeias musculares em alteração. Objetivo: Analisar o efeito de uma sessão de RPG na postura de mulheres com encurtamento da cadeia muscular anterior. Métodos: Trinta voluntárias ( $20 \pm 2,4$ anos) com encurtamento da cadeia anterior foram divididas aleatoriamente em dois grupos: grupo experimental e grupo controle. No grupo experimental foi aplicada a postura de RPG (40 min), e no grupo controle, as participantes não foram submetidas a nenhum procedimento. Foram mensuradas 11 variáveis relacionadas à análise postural por meio da fotometria, antes e imediatamente após a técnica de reeducação postural. Resultados: Algumas variáveis relacionadas à posição da cabeça e do ombro apresentaram alterações significativas: o ângulo de protusão da cabeça $(p=0,00)$, o alinhamento horizontal da cabeça $(p=0,02)$, distância fio de prumo-trago $(p=0,00)$ e distância fio de prumo-acrômio $(p=0,00)$. Conclusão: A técnica de reeducação postural global apresentou efeito imediato na posição da cabeça e do ombro, porém uma única intervenção não foi capaz de alterar o posicionamento de outras estruturas analisadas, como o tronco, a pelve e o membro inferior.

Palavras-chave: Exercícios de alongamento muscular. Fotometria. Postura. Fisioterapia. 
Abstract

Introduction: Global posture reeducation (GPR) is an evaluation and treatment method to several postural dysfunctions that use through global postures to treat alterations on muscular chains. Objective: to analyze the effect of one session of GPR in the posture of women with shortened anterior muscular chain. Methods: Thirty volunteers (20 \pm 2.4 years) with shortened anterior chain were divided randomly in two groups: experimental group and control group. In the experimental group GPR was applied for $40 \mathrm{~min}$, and in the control group, the participants were not submitted to any procedure. Eleven related variables were measured to analyze posture through photometry, before and immediately after GPR technique. Results: The related variables to head and shoulder presented significant modifications as: the angle of head protrusion $(p=0.00)$, the head's horizontal alignment $(p=0.02)$, distance plum-line through ear ( $p=0.00)$ and distance plumb-line through acromy $(p=0.00)$. Conclusion: GPR induced immediate effect in the head's and shoulder position; however a single intervention of GPR was not able to alter the positioning of other analyzed structures, as trunk, pelvis and inferior limb.

Keywords: Muscle stretching exercises. Photometry. Posture. Physiotherapy.

\section{Introdução}

Os hábitos posturais inadequados executados durante toda a vida, associados ao uso assimétrico do corpo humano durante as atividades funcionais podem ocasionar desequilíbrio do sistema neuromuscular e, consequentemente, alterações posturais $(1,2)$. Atualmente, as alterações posturais são consideradas problemas de saúde pública, pois apresentam alta incidência, o que é um fator preocupante, porque pode levar a incapacidades futuras (3).

A boa postura é definida como uma situação em que cada segmento corporal tem seu centro de gravidade orientado verticalmente sobre os segmentos adjacentes, de modo que suas posições sejam interdependentes (4), gerando menor gasto de energia (5). $\mathrm{Na}$ situação de alinhamento corporal adequado, as estruturas musculoesqueléticas estão equilibradas, portanto menos propensas a lesões ou deformidades (6).

O desgaste sofrido pelo corpo humano, graças às próprias atividades da vida diária e profissional, pode ser agravado pela adoção de posturas inadequadas, as quais ocasionam uma sobrecarga nas estruturas de suporte (7). Os mecanismos pelos quais as alterações posturais podem levar à dor podem ser a pressão sobre uma raiz nervosa, a tensão nas estruturas que contém terminações nervosas, espasmos musculares, encurtamentos adaptativos, instabilidade articular entre outras (8).

Existem atualmente muitas técnicas de tratamento com o objetivo de melhorar a postura, dentre elas a Reeducação Postural Global (RPG) (9-12).
Trata-se de uma técnica de tratamento fisioterapêutico que aplica posturas ativas e simultâneas, isométricas em posições excêntricas dos músculos da estática aplicadas em decoaptação articular progressiva (9-11).

A técnica de RPG preconiza a utilização de posturas específicas para o alongamento de músculos organizados em cadeias musculares, proporcionando o posicionamento correto das articulações e o fortalecimento dos músculos, os quais corrigem disfunções, não só da coluna vertebral, como também de outras articulações (10). 0 alongamento global alonga vários músculos simultaneamente, pertencentes à mesma cadeia muscular, e parte do pressuposto de que um músculo encurtado cria compensações em músculos próximos ou distantes (11). Desta forma, se ocorrer um encurtamento da cadeia muscular anterior, haverá a projeção da cabeça anteriormente, anteriorização dos ombros, aumento da cifose torácica, joelhos e calcâneo valgo e pés planos (10).

As posturas de RPG foram assim descritas: "rã no chão com braços abertos e fechados, rã no ar com braços abertos e fechados, em pé contra a parede, em pé no centro, postura sentada e postura em pé com inclinação anterior" (9).

A postura "rã no chão" tem como objetivo o alongamento dos músculos e fáscias da cadeia anterior, tais como o sistema suspensor do diafragma e das vísceras, músculos esternocleidomastoideo (ECM), reto anterior maior e menor do pescoço e escalenos, tendão do diafragma, músculo iliopsoas, trato ílio-tibial, músculos adutores e o músculo tibial anterior (13). 
Embora a técnica seja muito difundida em países, como Brasil, França, Itália e Espanha, e diversos fisioterapeutas utilizarem a técnica com resultados empíricos (14), poucos estudos são encontrados sobre a técnica de RPG (14-21).

Alguns demonstraram a sua eficácia no tratamento da incontinência urinária (17), espondilite anquilosante $(15-16,18)$, dor crônica de quadril (14), melhora das funções respiratórias (18-20) e melhora do centro de força corporal (21). Em relação ao efeito agudo do RPG sobre a postura, nenhum estudo foi encontrado até o momento.

A importância do presente estudo em analisar o efeito agudo da reeducação postural global, se baseia na hipótese de modificar o alinhamento corporal imediatamente após a técnica e consequentemente reduzir a sobrecarga nas articulações e músculos em tensão $(22,23)$. Dessa forma, o objetivo deste estudo foi analisar a postura de mulheres jovens com encurtamento da cadeia anterior, imediatamente após uma única intervenção da técnica de RPG.

\section{Materiais e métodos}

\section{Casuística}

Foi realizado um estudo clínico experimental, randomizado, controlado e cego (24). A pesquisa foi realizada no Laboratório de Comportamento Motor da Universidade Estadual do Centro-Oeste, Guarapuava, PR, e foi aprovado pelo Comitê de Ética pela mesma Universidade sob protocolo n. 12750/2008 conforme resolução 196/96 CNS. Todos os voluntários foram informados sobre a pesquisa e assinaram o Termo de Consentimento Livre e Esclarecido (TCLE).

Participaram voluntariamente do estudo 30 mulheres jovens, saudáveis, com idade: $20( \pm 2,4)$ anos, estatura: $169( \pm 5) \mathrm{cm}$, massa corporal total: $59( \pm 9,5) \mathrm{Kg}$ e Índice de Massa Corporal (IMC): $19,9( \pm 2,5) \mathrm{Kg} / \mathrm{m}^{2}$. O IMC foi baseado na equação do World Health Organization Diet Nutrition and prevention of chronic diseases (25). Como critérios de inclusão, foram selecionadas mulheres jovens entre 18 e 26 anos, que apresentavam encurtamento da cadeia muscular anterior, avaliada previamente pela fotometria no plano sagital. Foi observado o desalinhamento de três pontos de referência postural: occipto (C0), oitava vértebra torácica (T8) e terceira vértebra sacral (S3) e/ou associação da cabeça e ombro protusos, hipercifose torácica e anteroversão pélvica (8). Foram excluídos da pesquisa, através de avaliação clínica, as participantes que apresentaram dor ou patologia osteomioarticular.

Em relação aos sujeitos da pesquisa, estes foram distribuídos de forma aleatória, por sorteio, sendo o grupo experimental (GE) constituído de $20 \mathrm{mu}$ lheres que realizaram a técnica de reeducação postural global e o grupo controle (GC), constituído de 10 mulheres que permaneceram sentadas no local o tempo de procedimento da técnica de RPG (40 min), porém não realizaram nenhum procedimento. No GC houve uma perda amostral de 10 participantes.

\section{Métodos}

Para aquisição dos dados, foi usada uma máquina fotográfica digital (Canon IXUS 65, 6.0 megapixels), posicionada sobre um tripé a uma altura da metade da estatura das participantes, distância de $300 \mathrm{~cm}$ do sujeito e $350 \mathrm{~cm}$ da parede (26). As fotografias foram obtidas em posição ortostática, no plano sagital esquerdo e direito, já que o objetivo principal do estudo era uma análise da cadeia anterior. Pontos anatômicos específicos foram marcados com caneta dermográfica, para a colocação exata das esferas de isopor de $1 \mathrm{~cm}$ de diâmetro, as quais foram fixadas com fita adesiva dupla face (26).

Os pontos anatômicos marcados foram: trago da orelha, acrômio, processo espinhoso C7, espinha ilíaca ântero-superior, espinha ilíaca póstero-superior, trocanter maior do fêmur, linha articular do joelho, centro da patela, maléolo lateral e ponto entre a cabeça do segundo e terceiro metatarso, conforme o protocolo do software para Avaliação Postural $\left(\mathrm{SAPo}^{\circledR}\right.$ v. 0.68) (26) (Figura 1).

Após a coleta dos dados antropométricos, as participantes foram instruídas a se posicionarem em pé sobre uma borracha preta de Etil Vinil Acetato (EVA). Com o intuito de obter uma postura o mais natural possível, os participantes marcharam no lugar por 10 segundos (6). A impressão plantígrada foi registrada com giz branco sobre o EVA escuro para preservar a posição e dimensões da base nos diferentes planos fotografados antes e após a postura de RPG (6). A referência vertical foi obtida a partir de um fio de prumo marcado a cada $10 \mathrm{~cm}$ e fixado ao teto. 0 alinhamento horizontal do piso, do tripé e da máquina foi aferido com um nível de madeira (6). 


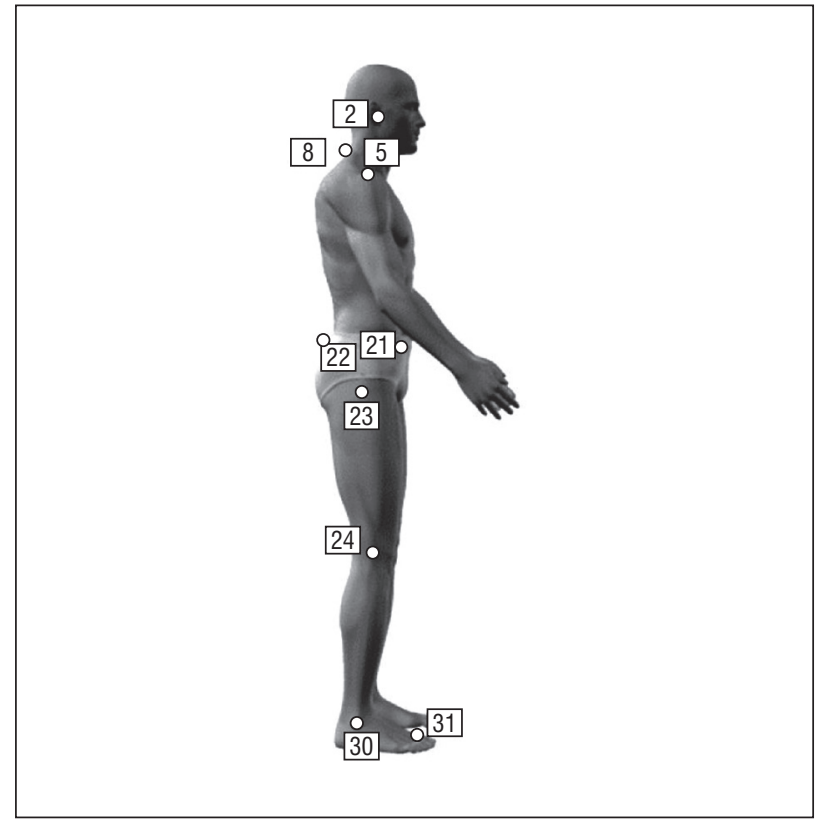

Figura 1 - Pontos anatômicos de referência no plano sagital utilizados no $\mathrm{SAPO}^{\circledR}$. Alinhamento horizontal da cabeça (C7): 2-8 e horizontal, alinhamento vertical do tronco: 5-23 e vertical, ângulo do quadril (tronco e membro inferior): 5-23-30, ângulo do joelho: 23-24-30 (ângulo posterior), ângulo tíbio-társico: 24-30 e horizontal. SAPo ${ }^{\circledR}$ : software para Avaliação Postural

\section{Protocolo experimental}

Após a primeira análise pela fotometria, a participante (GE) foi submetida a uma sessão de RPG, que constou inicialmente da postura "rã no chão com braços fechados", realizada conforme preconizado por Souchard (10), sendo esta postura realizada duas vezes para maior eficácia. Cada participante foi posicionado em decúbito dorsal, estando o mento, o esterno e o púbis alinhados na linha média. Realizou-se a pompage "encaixe" do sacro e a correção dos ombros com o "encaixe" de escápula por meio do deslizamento caudal desta. Os membros inferiores foram colocados inicialmente em $60^{\circ} \mathrm{de}$ abdução, $90^{\circ}$ de rotação externa e $45^{\circ}$ de flexão de quadril, $90^{\circ}$ de flexão de joelhos, mantendo a face plantar dos pés em aposição e voltadas para a linha média. Os membros superiores foram inicialmente colocados em $45^{\circ}$ de abdução de ombro, antebraço supinado e com os cotovelos, punho e dedos estendidos. A posição inicial da postura de rã no chão é visualizada na Figura 2.
Durante a realização da postura, o terapeuta utilizou comandos verbais, solicitando a manutenção do alinhamento e das correções posturais necessárias, com o objetivo de otimizar o alongamento muscular e impedir as compensações. 0 voluntário era então solicitado a realizar inspirações suaves, seguidas de expirações prolongadas, com o máximo rebaixamento possível das costelas e protusão do abdômen, visando o alongamento da cadeia muscular inspiratória, enquanto o terapeuta realizava uma leve tração occipital. Três correções "autoativas" foram ensinadas previamente ao participante e solicitadas durante a postura após cada expiração, aumentando a eficácia do método de alongamento proposto, são elas: correção do ombro no sentido da maca (posteriorização do ombro), "encaixe do queixo" (flexão da cervical alta e extensão da cervical baixa) e "encaixe lombar" (retificação lombar).

Após o participante estar posicionado na postura, este permaneceu por quatro minutos e realizou mais três repetições de quatro minutos cada uma, com um minuto de intervalo entre as repetições, totalizando 20 minutos (14). Em cada repetição da postura houve evoluções (variantes) no membro superior de $30^{\circ}$ no sentido da abdução e no membro inferior de $15 \mathrm{~cm}$ de deslizamento caudal dos pés, desta forma ocorreu uma abertura progressiva do ângulo do ombro e quadril respectivamente. Para alguns sujeitos, foi necessário utilizar alguns calços de EVA de $0,5 \mathrm{~cm}$ de espessura no occipto, graças à acentuada anteriorização da cabeça.

Todos os participantes do (GE) foram colocados na postura de reeducação postural global por apenas

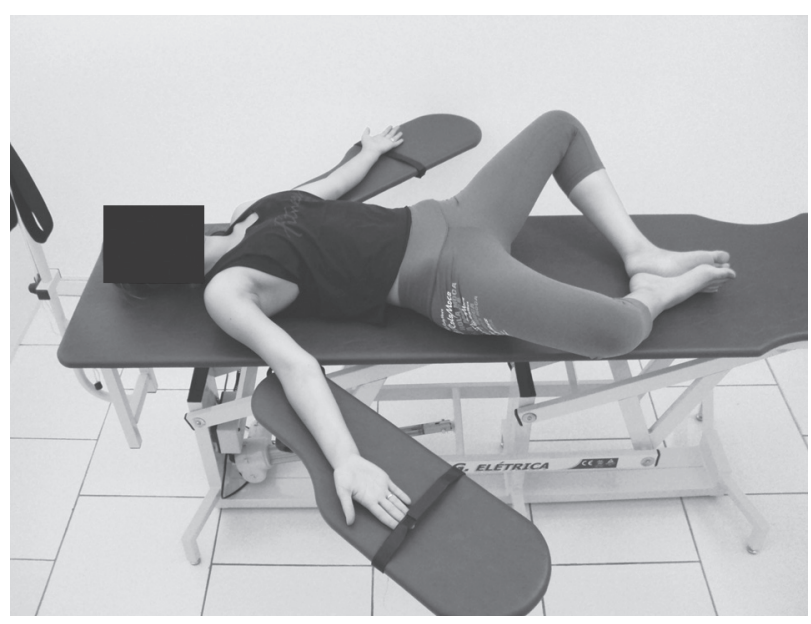

Figura 2 - Representação da postura "rã no chão" do método RPG empregada no estudo 
um fisioterapeuta que domina a técnica e que apresenta formação específica. Imediatamente $( \pm 1 \mathrm{~min})$ após o término da postura foi realizada a reavaliação fotométrica. Dessa forma, apenas um examinador realizou as avaliações fotométricas, enquanto o outro examinador apenas aplicou a técnica de RPG, caracterizando um estudo cego, pois durante a análise no $\mathrm{SAPo}^{\circledR}$, o examinador não sabia quem eram os sujeitos do grupo controle ou do grupo experimental.

Quando utilizado o programa $\mathrm{SAPo}^{\circledR}$, o examinador calibrou a referência vertical da fotografia em $100 \%$ de visualização e adotou a medida de $70 \mathrm{~cm}$ sobre o fio de prumo previamente marcado (26). A partir disso, foram analisadas as seguintes variáveis no plano sagital: alinhamento horizontal da cabeça, distância fio de prumo-trago, distância fio de prumo-acrômio, alinhamento vertical do tronco, ângulo do quadril, distância fio de prumo-trocânter maior, distância fio de prumo-linha articular do joelho e ângulo do joelho. Além dessas variáveis, foram analisados três ângulos, o ângulo de protusão da cabeça (PC), o ângulo da báscula de pelve (BP) e o ângulo tibiotársico (ATT), de acordo com a Figura 3.

As distâncias entre o fio de prumo e as estruturas supracitadas foram mensuradas em centímetros

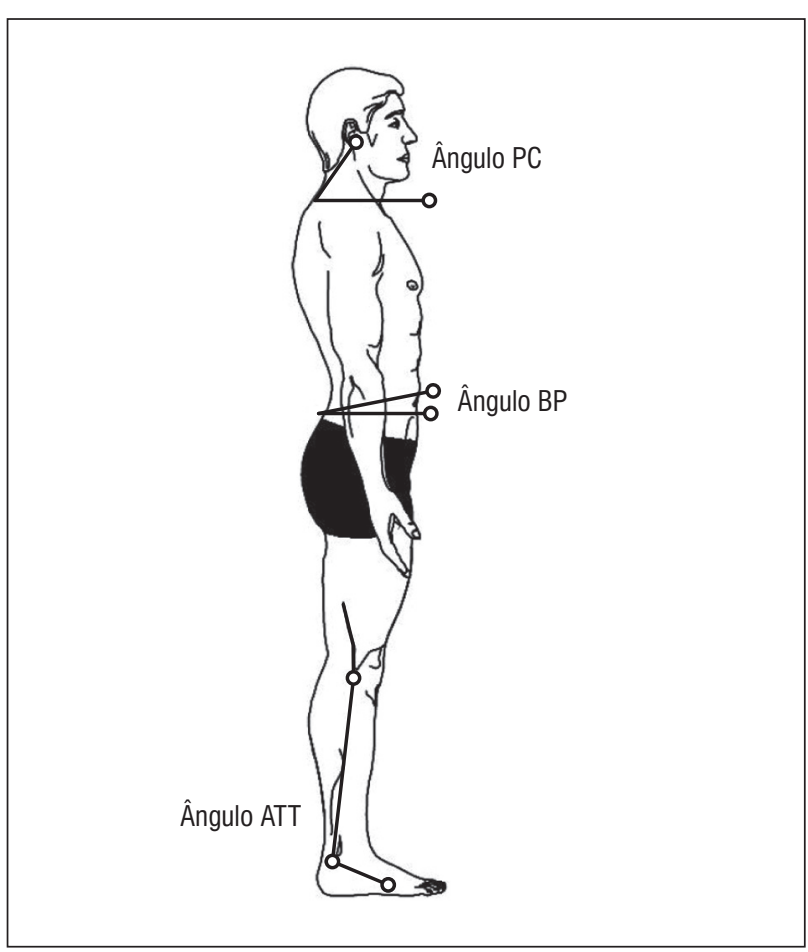

Figura 3 - Vista lateral demonstrando: ângulo de protusão da cabeça (PC), ângulo da báscula de pelve (BP) e ângulo da articulação tibiotársica (ATT) por meio do $\mathrm{SAPo}^{\circledR}$, por meio da colocação do fio de prumo levemente anterior ao maléolo lateral.

\section{Análise estatística}

A amostra se caracterizou homogênea após a aplicação do teste de Levene. Não houve diferença significativa $(p \leq 0,05)$ entre os grupos intervenção e controle, em relação à idade, massa corporal total, estatura e IMC. Para os demais resultados, foi utilizado o teste Shapiro-Wilk para verificar a normalidade dos dados. Como os dados não se apresentaram normais, foi utilizado a estatística não paramétrica por meio do teste Wilcoxon com significância de $p \leq 0,05$. Para isso foi utilizado o programa SPSS 17.0 for Windows (SPSS Inc., Chicago, IL).

\section{Resultados}

Todas as variáveis analisadas pela fotometria: ângulo de protusão da cabeça, alinhamento horizontal da cabeça, distância fio de prumo-trago, distância fio de prumo-acrômio, alinhamento vertical do tronco, ângulo da báscula de pelve, ângulo do quadril, distância fio de prumo-trocânter maior, ângulo do joelho, distância fio de prumo-linha articular do joelho, ângulo tibiotársico não demonstraram diferença significativa $(p>0,05)$ entre a vista lateral esquerda e a vista lateral direita, dessa forma, foi padronizada antes e após a técnica de RPG a vista lateral direita como referência no estudo.

Não foi encontrada diferença significativa $(\mathrm{p}>$ $0,05)$, em ambos os grupos analisados, nas seguintes variáveis: o alinhamento vertical do tronco, o ângulo da báscula de pelve, o ângulo do quadril, a distância fio de prumo-trocânter maior, o ângulo do joelho, a distância fio de prumo-linha articular do joelho e o ângulo tibiotársico.

Porém, no GE o ângulo de protusão da cabeça aumentou $5^{\circ} \pm 0,2\left(58^{\circ} \pm 3\right.$ vs $\left.53^{\circ} \pm 4, \mathrm{p}=0,003\right)$ e o alinhamento horizontal da cabeça seguiu o mesmo comportamento do ângulo PC $\left(59^{\circ} \pm 5\right.$ vs $\left.54 \pm 5, \mathrm{p}=0,02\right)$ após a técnica de RPG. Já a distância fio de prumo-trago diminuiu $2,1 \pm 0,2 \mathrm{~cm}(6,2 \pm 1 \mathrm{~cm} v s 8,3 \pm 2 \mathrm{~cm}, \mathrm{p}=$ 0,005 ), e a distância fio de prumo-acrômio diminuiu $2,2 \pm 0,3 \mathrm{~cm}(3,3 \pm 1 \mathrm{~cm}$ vs $5,5 \pm 1 \mathrm{~cm} \mathrm{p}=0,005)$, após a técnica de RPG. A diferença relativa entre o pré e o pós para ambos os grupos, está descrita na Tabela 1. 
Tabela 1 - Diferença relativa nas variáveis avaliadas. Os dados estão expressos em média e desvio-padrão.

* Diferença significativa $p<0,05$ quando comparado o grupo experimental (GE) e o grupo controle (GC)

\begin{tabular}{lccc}
\hline Variável & RPG $(\mathbf{n}=\mathbf{2 0})$ & Controle $(\mathbf{n}=\mathbf{1 0})$ & valor de $\mathbf{p}$ \\
\hline Ângulo de protusão da cabeça $\left(^{\circ}\right)$ & $5,0 \pm 0,2$ & $0,9 \pm 0,1$ & $0,003^{*}$ \\
Alinhamento horizontal da cabeça $\left(^{\circ}\right)$ & $5,0 \pm 0,1$ & $1,0 \pm 0,2$ & $0,020^{*}$ \\
Distância fio de prumo-trago $(\mathrm{cm})$ & $2,1 \pm 0,2$ & $0,1 \pm 0,03$ & $0,005^{*}$ \\
Distância fio de prumo-acrômio $(\mathrm{cm})$ & $2,2 \pm 0,3$ & $0,1 \pm 0,02$ & $0,005^{\star}$ \\
Alinhamento vertical do tronco & $0,0 \pm 0,6$ & $0,1 \pm 0,4$ & 0,86 \\
Ângulo da báscula de pelve $\left(^{\circ}\right)$ & $0,6 \pm 0,9$ & $0,4 \pm 0,5$ & 0,54 \\
Ângulo do quadril $\left(^{\circ}\right)$ & $-1,1 \pm 0,4$ & $-1,0 \pm 0,5$ & 0,78 \\
Distância fio de prumo-trocânter maior $(\mathrm{cm})$ & $0,7 \pm 0,6$ & $0,3 \pm 0,6$ & 0,14 \\
Ângulo do joelho $\left(^{\circ}\right)$ & $-1,8 \pm 0,3$ & $0,1 \pm 0,4$ & 0,08 \\
Distância fio de prumo-linha articular do joelho $(\mathrm{cm})$ & $0,9 \pm 0,4$ & $0,5 \pm 0,3$ & 0,26 \\
Ângulo tibiotársico $\left(^{\circ}\right)$ & $1,0 \pm 0,2$ & $0,8 \pm 0,3$ & 0,67 \\
\hline
\end{tabular}

Fonte: Dados da pesquisa.

\section{Discussão}

No presente estudo, pôde-se observar que modificações angulares importantes foram detectadas pela fotometria, após uma única sessão de RPG, principalmente nos segmentos cabeça e ombro. Várias hipóteses podem ser postuladas para explicar essas modificações, tanto modificações mecânicas (2729), caracterizadas por mudanças nas propriedades viscoelásticas das estruturas musculotendíneas, como modificações neurais caracterizadas por influência do fuso muscular, órgão tendinoso de Golgi e receptores articulares (27-29).

Inicialmente, a posteriorização da cabeça no grupo experimental pode ser atribuída à leve tração exercida pelo examinador na região occiptal do sujeito durante todo o período da postura ( $\pm 32 \mathrm{~min}$ ), proporcionando um afastamento axial de toda a coluna vertebral. A leve tração cervical poderia ter desencadeado uma redução da atividade gama nos músculos cervicais, ou ainda, uma deformação elástica no tecido conjuntivo de pequenos músculos como escalenos, ECM, reto maior e menor, e por último o aumento de comprimento nas fáscias presentes na região cervical, principalmente a fáscia cérvico-tóraco-abdominal e a lâmina fibrosa pré-vertebral (11). Já o aumento do número de sarcômeros em série, proposto por Vanti et al. (13), não explicaria tal modificação, pois é sabido que esse fenômeno pode ocorrer efetivamente durante o alongamento crônico, isto é, realizado ao longo de semanas (30-32).

Outra hipótese a ser considerada, é que a simples descompressão das estruturas vertebrais ocorrida pela tração axial foi capaz de modificar a posição da cabeça após a técnica de RPG. Talvez, essas diferenças no posicionamento sejam momentâneas pelo pequeno volume de alongamento proporcionado em uma única sessão, assim esse pequeno estímulo pode não ser suficiente para gerar uma deformação plástica no músculo esquelético (28).

Movimentos torácicos no sentido expiratório durante cada respiração do participante, também podem explicar o ganho de comprimento da fáscia cérvico-tóraco-abdominal, graças à sua inserção, e assim modificar a posição da cabeça posteriormente, visto que o encurtamento dessa fáscia pode levar à protusão da cabeça e retificação cervical (9). Para Lapierre (33), modificações posturais não devem ser atribuídas somente à plasticidade dos tecidos envolvidos, e sim a uma reprogramação psicomotora e proprioceptiva que modifica o esquema corporal do indivíduo submetido a um programa de reeducação postural global.

0 ângulo do alinhamento horizontal da cabeça em relação à C7, quando reduzido, determina a posição anteriorizada da cabeça, sendo que no presente 
estudo antes da utilização da técnica, o ângulo era de $54^{\circ}$ e após era de $59^{\circ}$, ocorrendo uma posteriorização da cabeça de $5^{\circ}$. Resultado semelhante foi encontrado para o ângulo de protusão da cabeça (PC). $\mathrm{O}$ aumento desse ângulo e consequentemente a verticalização da cabeça poderia ser suficiente para reduzir a dor em pacientes que apresentam cervicalgia (4), cefaleia tensional e disfunção temporomandibular (22-23). Não é possível comparar as variáveis alinhamento horizontal da cabeça e ângulo de protusão da cabeça porque não há na literatura relatos sobre valores de normalidade da posição da cabeça. Em relação à modificação da posição do ombro, esta pode ter ocorrido por causa do posicionamento da escápula durante a postura, que se traduz em um rolamento da escápula no sentido caudal, levando o acrômio a uma posteriorização. Músculos que anteriorizam o ombro, como, por exemplo, o encurtamento do peitoral menor (8), podem ter sofrido as mesmas modificações dos músculos cervicais já citadas anteriormente. Esses achados vêm ao encontro do estudo de Moreira e Soares (35), que, utilizando avaliações radiográficas, observaram uma mudança na posição do ombro após o período de tratamento com RPG de oito semanas. Diferente do presente estudo, que só analisou o efeito agudo da RPG, Moreira e Soares (35) relatam que essas modificações encontradas na posição do ombro foram perpetuadas após o período de quatro meses sem tratamento algum, indicando que os ganhos de flexibilidade foram mantidos, visto não haver diferenças entre as medidas encontradas uma semana após a alta terapêutica e quatro meses depois desta.

Observou-se que em outras regiões do corpo, como tronco, pelve e membro inferior, não ocorreu o mesmo comportamento encontrado na cabeça e no ombro. Conforme a Lei de Hooke (36), o grau de deformação é igual à força aplicada multiplicada pelo tempo de aplicação; dessa forma, nenhuma alteração pode ter sido encontrada nessas regiões pelo pequeno volume de alongamento (apenas uma sessão), pela presença de músculos grandes ou pela tração exercida pelo terapeuta no occipto não ter influenciado de forma efetiva a região do tronco, pelve e membro inferior. Mesmo sendo a RPG uma técnica global, outra hipótese provável que explique nenhuma diferença no posicionamento dos membros inferiores é que a postura utilizada no estudo, a rã no chão, enfatiza o alongamento nos segmentos da cabeça e coluna, (9) em virtude da tração e da ausência de carga axial na coluna, enquanto as posturas em pé enfatizam os membros inferiores, conforme preconiza Souchard (9). No entanto, foi escolhida a postura rã no chão por ser a postura clássica para indivíduos com encurtamento da cadeia anterior (11).

Uma modificação elástica nos tecidos, apesar de não ser medida neste estudo, pode ter ocorrido, pois houve mudanças na posição da cabeça e do ombro; porém, uma única intervenção não foi suficiente para modificar segmentos corporais importantes como o tronco, a pelve, o joelho e o tornozelo.

0 efeito agudo da RPG sobre a pressão plantar foi mensurado por meio de uma plataforma de pressão, e ficou evidente que imediatamente após a realização de uma única sessão de RPG houve recuperação da simetria corporal e readequação da distribuição das pressões de contato plantar, o que interferiu positivamente na localização do centro de força (21). No presente estudo, não foi realizada nenhuma análise baropodométrica, porém modificações no posicionamento de alguns segmentos como cabeça e ombro poderiam interferir no centro de força corporal.

Alguns estudos controlados e randomizados demonstraram eficácia no tratamento da espondilite anquilosante, a partir de um tratamento de reeducação postural global em longo prazo $(15-16,18)$. Fernández-de-las-Peñas et al. (15) trataram pacientes com espondilite anquilosante durante quatro meses e observaram melhora da mobilidade do esqueleto axial após a realização da técnica de RPG, utilizando medidas de mobilidade do Bath Ankylosing Spondylitis Disease Metrology Index (BASMI) e Bath Ankylosing Spondylitis Functional Index (BASFI). Com um seguimento de um ano referente ao estudo anterior, Fernandez et al. (16) observaram que os ganhos relativos à técnica de RPG se mantiveram significativos em relação ao grupo controle, demonstrando sua eficácia em longo prazo.

Apesar de o presente estudo analisar o efeito da RPG na postura, alguns estudos relatam que a função respiratória pode ser melhorada com a técnica de RPG, pois esta interfere diretamente na flexibilidade dos músculos respiratórios (18-20). Durmus et al. (18) relataram melhora da função respiratória em pacientes com espondilite anquilosante que receberam tratamento por meio da RPG, com ganhos nas variáveis picos de fluxo expiratório, volume expiratório forçado e capacidade vital. Outros estudos apontaram melhora das funções respiratórias, como pressão inspiratória 
máxima, pressão expiratória máxima, expansão torácica (19-20) e mobilidade abdominal (19). Essas funções foram aumentadas após o ganho de flexibilidade da musculatura da cadeia respiratória.

Algumas limitações ocorreram no presente estudo. Em função da dificuldade de medir o comprimento de músculos profundos, músculos pequenos e fáscias musculares, o estudo se baseou apenas na posição de segmentos corporais para a análise postural. Outro fator limitante encontrado foi a dificuldade de realizar a avaliação fotométrica da coluna torácica, uma vez que a escápula interfere na visualização de perfil.

Recomenda-se que mais estudos clínicos experimentais sejam desenvolvidos na área da reeducação postural, analisando variáveis ainda não estudadas, como o efeito de diferentes posturas de RPG, sua eficácia em diferentes patologias, ou analisar o seu efeito crônico sobre a postura, visando a aumentar o conhecimento científico sobre a influência da RPG na postura.

\section{Conclusão}

A técnica de Reeducação Postural Global, aplicada apenas uma vez, em mulheres jovens, foi suficiente para melhorar a posição da cabeça e do ombro, imediatamente após a utilização da técnica.

Dessa forma, a técnica de RPG pode ser indicada para pacientes que apresentam uma anteriorização da cabeça e/ou protusão de ombro. Entretanto, não se sabe por quanto tempo perduram esses efeitos. Talvez sejam necessárias mais sessões de RPG para modificar outras regiões do corpo, como tronco, pelve e membro inferior.

\section{Referências}

1. Moseley GL, Hodges PW. Reduced variability of postural strategy prevents normalization of motor changes induced by back pain: a risk factor for chronic trouble? Behav Neurosci. 2006;120(2):474-76.

2. Durkin JL, Harvey A, Hughson RL, Callaghan JP. The effects of lumbar massage on muscle fatigue, muscle oxygenation, low back discomfort, and performance during prolonged driving. Ergonomics. 2006; 49(1):28-44.
3. Braccialli L, Villarta R. Aspectos a serem considerados na elaboração de programas de prevenção e orientação de problemas posturais, Revista Paulista de Educação Física. 2000;14(2):159-71.

4. Bricot B. Posturologia. 2a ed. São Paulo: Ícone; 2001.

5. Basmajian JV. Electro-fisiologia de la acción muscular. Argentina: Médica Panamericana S.A.; 1976.

6. Santos MM, Silva MPC, Sanada L, Alves CRJ. Análise postural fotogramétrica de crianças saudáveis de 7 a 10 anos: confiabilidade interexaminadores. Rev Bras Fisioter. 2009;13(4):350-5.

7. Sacco I, Melo M, Rojas G, Naki I, Burgi K, Silveira L, et al. Análise biomecânica e cinesiológica de posturas mediante fotografia digital: estudo de caso. Rev Bras Ciênc Mov. 2003;11(2):25-33.

8. Kendall FP, McCreary EK, Provance PG. Muscles: testing and function, with posture and pain. 5th ed. Baltimore, MD: Lippincott Williams \& Wilkins; 2005.

9. Souchard PE. Reeducação postural global: método do campo fechado. 2a ed. São Paulo: Ícone; 1986.

10. Souchard PE. O stretching global ativo. 2a ed. São Paulo: Manole; 1996.

11. Souchard PE. Reeducação postural global: método do campo fechado. 4a ed. São Paulo: Ícone; 2001.

12. Souchard PE. Fundamentos da reeducação postural global: princípios e originalidade. 2a ed. São Paulo: É Realizações; 2003.

13. Vanti C, Generali A, Ferrari S, Nava T, Tosarelli D, Pillastrini P. Rééducation Posturale Globale in musculoskeletal diseases: scientific evidence and clinical practice. Reumatismo. 2007;59(3):192-201.

14. Cunha ACV, Burke TN, França FJR, Marques AP. Effect of global posture reeducation and of static stretching on pain, range of motion, and quality of life in women with chronic neck pain: a randomized clinical trial. Clinics. 2008;63(6):763-70.

15. Fernández-de-Las-Peñas C, Alonso-Blanco C, MoralesCabezas M, Miangolarra-Page JC. Two exercise interventions for the management of patients with ankylosing spondylitis: a randomized controlled trial. Am J Phys Med Rehabil. 2005;84(6):407-19. 
16. Fernández-de-Las-Peñas C, Alonso-Blanco C, AlguacilDiego IM, Miangolarra-Page JC. One-year follow-up of two exercise interventions for the management of patients with ankylosing spondylitis. Am J Phys Med Rehabil. 2006;85:559-67.

17. Fozzatti MCM, Palma P, Herrmann V, Dambros M. Impacto da reeducação postural global no tratamento da incontinência urinária de esforço feminina. Rev Assoc Med Bras. 2008;54(1):17-22.

18. Durmuş D, Alayl G, Uzun O, Tander B, Cantürk F, Bek $Y$, et al. Effects of two exercise interventions on pulmonary functions in the patients with ankylosing spondylitis. Joint Bone Spine. 2009;76(2):150-5.

19. Moreno MA, Catai AM, Teodori RM, Borges BLA, Cesar MC, Silva E. Effect of a muscle stretching program using the Global Postural Reeducation method on respiratory muscle strength and thoracoabdominal mobility of sedentary young males. J Bras Pneumol. 2007;33(6):679-686.

20. Teodori RM, Moreno MM, Fiore Jr. JF, Oliveira ACS. Alongamento da musculatura inspiratória por intermédio da Reeducação Postural Global (RPG). Rev Bras Fisioter. 2003; 7(1):25-30.

21. Teodori RM, Guirro ECO, Santos RM. Distribuição da pressão plantar e localização do centro de força após intervenção pelo método de reeducação postural global: um estudo de caso. Fisioter Mov. 2005; 18;(1):27-35.

22. Lee WY, Okeson JP, Lindroth J. The relationship between forward head posture and temporomandibular disorders. J Orofac Pain. 1995;9;(2):161-7.

23. Nicolakis P, Nicolakis M, Piehslinger E, Ebenbichler G, Vachuda M, Kirtley C, et al. Relationship between craniomandibular disorders and poor posture. Cranio. 2000;18(2):106-12.

24. Baumgartner TA, Hensley LD. Conduction and reading research in health and human performance. 4th ed. New York: McGraw-Hill; 2006.

25. World Health Organization (WHO). Diet nutrition and prevention of chronic diseases. Geneva: World Health Organization; 1990.

26. SAPO v. 0.68: Portal do projeto software para avaliação postural [internet]. São Paulo: Incubadora Virtual Fapesp; 2009 [acesso em: 11 out. 2009]. Disponível em: http://sapo.incubadora.fapesp.br/portal.
27. Cornwell A, Nelson AG, Sidaway B. Acute effects of stretching on the neuromechanical properties of the triceps surae muscle complex. Eur J Appl Physiol. 2002;86(5):428-34.

28. Avela J, Finni T, Liikavaiinio T, Niemelã E, Komi PV. Neural and mechanical responses of the triceps surae muscle group after $1 \mathrm{~h}$ of repeated fast passive stretches. J Applied Physiology. 2004;96,2325-32.

29. Weir DE, Tingley J, Elder GCB. Acute passive stretching alters the mechanical properties of human plantar flexors and optimal angle for maximal voluntary contraction. Eur J Appl Physiol. 2005;93(5-6): 614-23.

30. Coutinho EL, Gomes ARS, França CN, Oishi J, Salvini TF. Effect of passive stretching on the immobilized soleus muscle fiber morphology. Braz J Med Biol Res. 2004;37(12):1853-61.

31. Boakes JL, Foran J, Ward SR, Lieber RL. Muscle adaptation by serial sarcomere addition 1 year after femoral lengthening. Clin Orthop Relat Res. 2007;456: 250-3.

32. Gomes ARS, Coutinho EL, França CN, Polonio J, Salvini TF. Effect of one stretch a week applied to the immobilized soleus muscle on rat muscle fiber morphology. Braz J Med Biol Res. 2004;37(10):1473-80.

33. Lapierre A. Cinesiologia reeducação postural: reeducação psicomotora. 6a ed. São Paulo: Manole; 1987.

34. Iunes DH, Bevilaqua-Grossi D, Oliveira AS, Castro FA, Salgado HS. Análise comparativa entre avaliação postural visual e por fotogrametria computadorizada. Rev Bras Fisioter. 2009;13(4):308-15.

35. Moreira CMC, Soares DRL. Análise da efetividade da reeducação postural global na protusão do ombro após a alta terapêutica. Fisioter Mov. 2007;20(1): 93-99.

36. Hintzman DL. Robert Hooke's model of memory. Psychon Bull Rev. 2003;10:3-14.

Recebido: 28/12/2010 Received: $12 / 28 / 2010$

Aprovado: 18/03/2011 Approved: 03/18/2011 